\title{
Corrigendum: Luciferase-Based Screen for Post-Translational Control Factors in the Regulation of the Pseudo-Response Regulator PRR7
}

\author{
Yeon Jeong Kim and David E. Somers* \\ Department of Molecular Genetics, The Ohio State University, Columbus, $\mathrm{OH}$, United States
}

\section{OPEN ACCESS}

Edited and reviewed by: Frontiers in Plant Science, Frontiers Media SA, Switzerland

*Correspondence: David E. Somers somers.24@osu.edu

Specialty section: This article was submitted to Plant Abiotic Stress,

a section of the journal Frontiers in Plant Science

Received: 29 July 2019

Accepted: 30 July 2019

Published: 22 August 2019

Citation:

Kim YJ and Somers DE (2019)

Corrigendum: Luciferase-Based Screen for Post-Translational Control

Factors in the Regulation of the Pseudo-Response Regulator PRR7

Front. Plant Sci. 10:1057.

doi: 10.3389/fp/s.2019.01057
Keywords: circadian clock, pseudo-response regulator, PRR7, ELF3, ELF4, EMS mutagenesis, posttranslational regulation

\section{A Corrigendum on}

Luciferase-Based Screen for Post-translational Control Factors in the Regulation of the PseudoResponse Regulator PRR7

By Kim YJ and Somers DE (2019). Front. Plant Sci. 10:667. doi: 10.3389/fpls.2019.00667

There is an error in the Funding statement. The correct number for the "Next-Generation BioGreen21 Program" is "PJ01327305."A correction has therefore been made to the Funding statement:

"This work was supported by National Institutes of Health grant R01GM093285 and by a grant from the Next-Generation BioGreen21 Program (Systems and Synthetic Agrobiotech Center, Project PJ01327305), Rural Development Administration, Republic of Korea (DS).”

The authors apologize for this error and state that this does not change the scientific conclusions of the article in any way. The original article has been updated.

Copyright $\odot 2019$ Kim and Somers. This is an open-access article distributed under the terms of the Creative Commons Attribution License (CC BY). The use, distribution or reproduction in other forums is permitted, provided the original author $(s)$ and the copyright owner(s) are credited and that the original publication in this journal is cited, in accordance with accepted academic practice. No use, distribution or reproduction is permitted which does not comply with these terms. 